\title{
Incorporating Triggering and Environmental Factors in the Analysis of Earthquake-Induced Landslide Hazards
}

\author{
Ming Wang $\cdot$ Min Liu $\cdot$ Saini Yang $\cdot$ \\ Peijun Shi
}

Published online: 24 June 2014

(c) The Author(s) 2014. This article is published with open access at Springerlink.com

\begin{abstract}
Pingwu County of Sichuan Province was severely hit by the 12 May 2008 Wenchuan Earthquake and experienced widely distributed earthquake-induced landslides. We proposed an integrated method that incorporates landslide triggering factors embedded in the Newmark displacement computation and other environmental factors, expressed as lithology, land-use type, vegetation cover (Normalized Difference Vegetation Index, NDVI), elevation, and profile and plan curvature, in the analysis of earthquake-induced landslide hazards in the study area. The earthquake-induced landslide inventory of this area was obtained by visual interpretation of two highresolution SPOT-5 images before and after the earthquake. We used GIS tools to generate an equal number of landslide and non-landslide cell samples in a 30-m grid map, and assigned triggering and environmental variables to each cell. A logistic regression model was built to investigate the occurrence of earthquake-induced landslides. The results show that Newmark displacement (in which triggering factors are embedded) and lithology (as an environmental factor) were the two dominant variables controlling landslide occurrence. Other environmental factors, including NDVI, land-use type, and elevation, also significantly affected landslide occurrences. Overall $81.2 \%$ correctness was achieved in the regression model. The results confirm the predictive power of our method,
\end{abstract}

M. Wang $(\varangle) \cdot$ M. Liu $\cdot$ S. Yang $\cdot$ P. Shi

State Key Laboratory of Earth Surface Processes and Resource Ecology, Beijing Normal University, Beijing 100875, China

e-mail: wangming@bnu.edu.cn

M. Wang $\cdot$ M. Liu $\cdot$ S. Yang $\cdot$ P. Shi

Academy of Disaster Reduction and Emergency Management, Beijing Normal University, Beijing 100875, China which integrates both triggering and environmental factors in modeling earthquake-induced landslides.

Keywords Earthquake-induced landslides .

Environmental factors $\cdot$ Triggering factors $\cdot$ Hazard

analysis $\cdot$ Newmark displacement $\cdot$ Wenchuan

earthquake

\section{Introduction}

Landslides, defined as the movement of a mass of rocks, debris, or earth down a slope (Cruden 1991), globally cause large numbers of casualties and enormous property losses every year. Landslides can be triggered by different kinds of external stimuli, such as intense rainfall, earthquakes, and even some human activities. An earthquake can cause a large number of landslides if it occurs in a mountainous area, and can result in huge direct and indirect losses. For example, the Wenchuan earthquake of 12 May 2008 (magnitude 7.9) caused 5,117 new landslides in Sichuan Province, China that threatened 122 residential settlements and caused a direct economic loss of 43.801 billion yuan (7.2 billion USD) (NDRC-Ministry of Science and Technology/Expert Group on Earthquake Relief 2008).

Much research has been conducted on susceptibility assessment of earthquake-induced landslides from a range of perspectives, using different approaches. From the perspective of geomorphology, environmental factors describe the external conditions under which various numbers and sizes of slope failures may appear. It is crucial to build the relationship between environmental factors and landslide occurrence. Keefer (1984a, b) conducted field investigations and undertook a statistical study of earthquakeinduced landslides worldwide. $\mathrm{He}$ pointed out that 
earthquake-induced landslides often occurred in mountainous regions with slopes $>25^{\circ}$, elevations $>150 \mathrm{~m}$, recent erosion by a river or glacier, or severe breakdown of rocks. This was a significant attempt to statistically quantify the relationship between environmental factors (geomorphologic, geologic, and geographic) and landslide occurrence. In recent decades, important progress has been made by using regression analysis to investigate regional susceptibility. Correlation was established between factors representing topographic, geologic, and geographic features and earthquake-induced landslides (Keefer 2000; Baeza and Corominas 2001; Duman et al. 2006; GarcíaRodríguez et al. 2008, García-Rodríguez and Malpica 2010; Hasegawa et al. 2008; Lee et al. 2008; Meunier et al. 2008; Lee et al. 2010). The hazard analysis of Wenchuan earthquake-induced landslides conducted by Huang and $\mathrm{Li}$ (2008) and Qi et al. (2009) also summarized the relationship between the distribution of landslides and factors such as lithology, local topography, and geomorphology based on post-disaster field investigations and the interpretation of remote sensing data.

Investigation of environmental factors is essential for the hazard analysis of coseismic landslides, but the study of triggering factors is also necessary. Ground shaking is an important factor in triggering landslides, and it is investigated widely from an engineering ecology perspective. Keefer (1984a, b) summarized several characteristic relationships, including the relationship between the area affected by earthquake-induced landslides and the magnitude of the earthquake, the relationship between the distance from the epicenter to the farthest landslide site and the magnitude, and the relationship between the distance from the farthest landslide site to the rupture zone and the magnitude. Keefer also discussed the minimum seismic intensity experienced at the landslide locations. Newmark (1965) published a method to calculate rigid block sliding displacement, which established the relationship between ground motion parameters and rigid body displacement. The Newmark method is a widely accepted engineering geology approach for analyzing earthquake-induced landslides. Newmark displacement measures rigid block sliding displacement and is computed based on seismic motion, soil and rock properties, and topographic information. The calculated Newmark displacement can be used for assessing the probability of landslide occurrence. Landslide occurrences also can be statistically linked to regional geomorphology, geology, and geography based on various environmental variables. One successful example of applying Newmark's method was the Wilson and Keefer (1983) study of an earthquake-induced landslide during the 1979 California earthquake in the United States. In their study, the Newmark displacement of points within the landslide, calculated from seismic data, is consistent with the measured displacement. Continued use of Newmark analysis led to a simplification of the method by Jibson (1993), which approximates Newmark displacements from landslide critical acceleration and earthquake shaking intensity. Later, Jibson et al. (2000) adopted ARC/INFO Geographic Information System (GIS) software to estimate coseismic landslide displacements within each grid cell of a given area of interest. This enabled the construction of probability curves that relate predicted displacement to the probability of slope failure. The HAZUS Multi-hazard Loss Estimation Methodology Earthquake Model (FEMA 2003), developed by the U.S. Federal Emergency Management Agency (FEMA), uses a similar method to generate a spatial distribution of landslide hazard factors. The significance of Newmark displacement analysis is that it combines slope geometry, geological attributes, and earthquake ground motion parameters into a single-valued physical concept. If this value exceeds a certain threshold (usually 5-10 cm), the possibility of landslides on a slope increases dramatically. Newmark displacement values can successfully explain the triggering factors of earthquakeinduced landslides (Rajabi et al. 2011; Rodriguez-Peces et al. 2011).

The research presented in this article integrates both triggering and environmental factors in a regression model to predict the occurrence and distribution of landslides after a major earthquake. This regression model also helps us differentiate the contribution of various factors, and more importantly, analyzes the predictive power of the model when both triggering and environmental factors are considered.

The rest of this article is organized as follows. Section 2 describes the study area. In Sect. 3, we introduce the method used for the analyses and the data for both the triggering and the environmental factors, and present the regression model and its input variables. We focus on a discussion of the regression results in Sect. 4 and present conclusions in Sect. 5.

\section{Study Area}

The magnitude 7.9 Wenchuan earthquake of 2008 directly affected northeastern Sichuan, southern Gansu, and southwestern Shanxi Provinces of China. It caused a large number of casualties and significant property losses in the affected areas. The epicenter of the event was in Wenchuan County, which experienced extreme shaking with an intensity of XI. The earthquake was one of the most severe geological disasters in Chinese history.

The study area is located in the vicinity of the towns of Nanba, Shuiguan, and Bazi in Pingwu County, Mianyang, Sichuan. The area lies $180 \mathrm{~km}$ northeast of the Wenchuan 
Fig. 1 Earthquake affected area (a), Pingwu County (b), and the study area with landslide incidents (c). DEM digital elevation model. Source: Chinese Academy of Sciences (n.d.) (a)

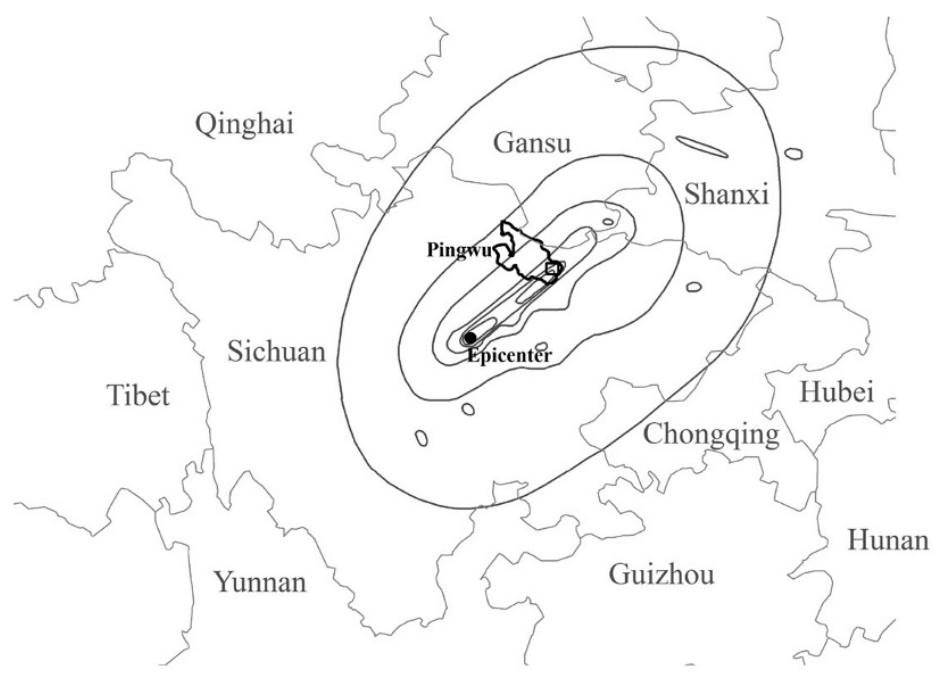

(b)

$\bigwedge^{N}$

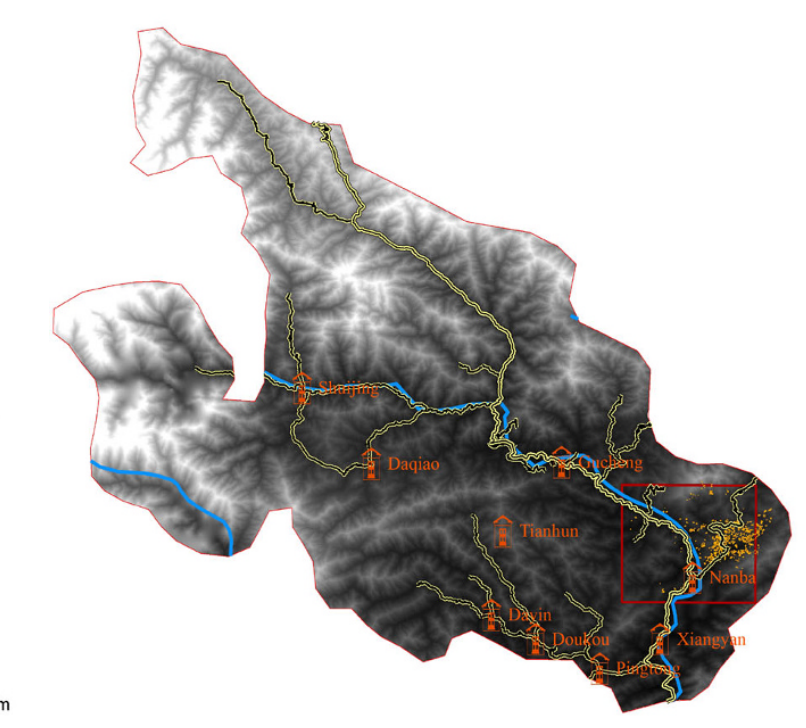

(c)

$\stackrel{N}{N}$

$\begin{array}{llll}0 & 5 & 10 & 20 \\ 0 & - & & \end{array}$

Town

Main roads

— Fujiang

DEM

High: 5365

Low: 607

Study area

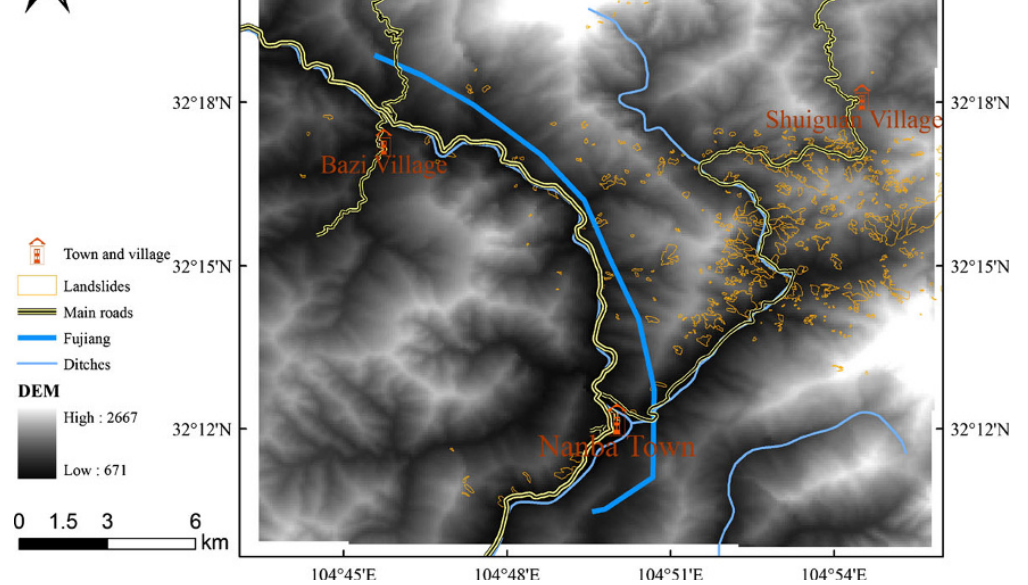


earthquake epicenter, and contains zones that were affected by seismic intensities of IX, X, and XI, as shown in Fig. 1 . It consists of mountainous topography with elevations ranging from 671 to 2,667 m. The Fujiang, Hongxigou, and Sunjiagou Rivers flow through the area (Fig. 1). A large number of landslides triggered by the Wenchuan earthquake in this area occurred along the highways and rivers.

Pingwu County experiences a northern subtropical mountainous humid monsoon climate, characterized by four distinct seasons as well as cloudy but not very foggy weather. The annual average temperature is $14.7^{\circ} \mathrm{C}$, with an extreme high of $37^{\circ} \mathrm{C}$ and an extreme low of $-7{ }^{\circ} \mathrm{C}$. The annual average precipitation is about $800 \mathrm{~mm}$.

\section{Methods and Data}

This section introduces the data used in this study including the inventory of landslides caused by the Wenchuan earthquake, the variables (seismic acceleration, slope angle, soil properties, and so on) used for Newmark displacement calculation, and other environmental factors that contributed to the occurrence of landslides. Methods of calculating Newmark displacement and integrating all factors into a regression model are both presented and discussed.

\subsection{Landslide Inventory}

Landslides susceptibility research was severely hampered by the deficiency of landslide inventory data in the past (van Westen et al. 2006; Lee 2009; Wasowski et al. 2011). With the rapid advancement of remote sensing technologies and applications, many researchers have successfully employed remote sensing images and interpretation methods to generate and expand landslide inventories (Sarkar and Kanungo 2004; Nichol and Wong 2005; Tralli et al. 2005; Proske et al. 2008; Jaiswal et al. 2011; Yang et al. 2013). In this article, an event-based landslide inventory has been built for our study area by visual interpretation of two SPOT-5 satellite composite images acquired on 5 September 2006 and 4 June 2008. The former image was taken before the Wenchuan earthquake main shock and the latter shortly after. To ensure reliability and accuracy of the landslide inventory maps, we compared the Wenchuan data with landslide data sets compiled by the China Institute of Geo-Environment Monitoring (2009) and $\mathrm{Xu}$ and $\mathrm{Li}$ (2010), and conducted field investigations in the study area in 2011 and 2012. The final landslide inventory map is shown in Fig. 2. Figure $2 b$ shows the overall landslides distribution in the study area compared with the same area before the earthquake, as shown in Fig. 2a. Figure $2 \mathrm{~d}$ shows the zoomed-in sample area with landslides details compared with the same area before the earthquake, as shown in Fig. 2c.

\subsection{Newmark Displacement}

We adopted the methodology proposed by Jibson et al. $(1998,2000)$ to generate a map of the factor of safety (FS) for the study area. The factor of safety was computed based on the simplified limit-equilibrium model (Jibson et al. 1998).

$\mathrm{FS}=\frac{c^{\prime}}{\gamma t \sin \alpha}+\frac{\tan \phi^{\prime}}{\tan \alpha}-\frac{m \gamma_{w} \tan \phi^{\prime}}{\gamma \tan \alpha}$

where $c^{\prime}$ is effective cohesion, $\phi^{\prime}$ is effective friction angle, $\alpha$ is slope angle, $\gamma$ is material unit weight, $\gamma_{w}$ is the unit weight of water, $t$ is slope-normal thickness of the failure slab, and $m$ is the proportion of slab thickness that is saturated.

A 30-m digital elevation model (DEM), downloaded from the International Scientific Data Service Platform (Chinese Academy of Sciences n.d.), was used to generate a slope map in the study area. Representative values of the frictional and cohesive components of soil shear strength were assigned to each geologic unit. The values of shear strength for soils in the study area were determined based on: (1) a soil database assembled by the Nanjing Institute of Soil Science, Chinese Academy of Sciences, which is the standard for classification of soil texture in China ( $\mathrm{Li}$ et al. 2003), and (2) referenced data from the engineering manual for that particular area (Liu et al. 2011). The value of $t$ was set as $2 \mathrm{~m}$ and $\gamma$ was set as $16 \mathrm{kN} / \mathrm{m}^{3}$ by considering the average property of soil components in the study area; groundwater depth was not taken into account (Li et al. 2003; Liu et al. 2011). Using Eq. 1, a factor of safety map (Fig. 3a) was generated using ARC/INFO GIS software. Grid cells with slopes less than $5^{\circ}$ were not analyzed.

Critical acceleration is a function of the FS and slope angle, and it can be calculated by Eq. 2,

$\mathrm{a}_{c}=(\mathrm{FS}-1) g \sin \alpha$

A map of critical acceleration for the study area is shown in Fig. $3 b$.

Arias intensity, $\mathrm{I}_{\alpha}$, is a comprehensive measure of ground shaking intensity developed by Arias (1970), Jibson (1993). Mathematically, $I_{\alpha}$ is the integral of the square of acceleration over time, expressed as:

$\mathrm{I}_{\alpha}=\pi / 2 \mathrm{~g} \int[\alpha(t)]^{2} \mathrm{~d} t$

where $\alpha(t)$ is the ground acceleration as a function of time and usually is recorded by strong motion seismographs during earthquake events. Alternatively, there are empirical 

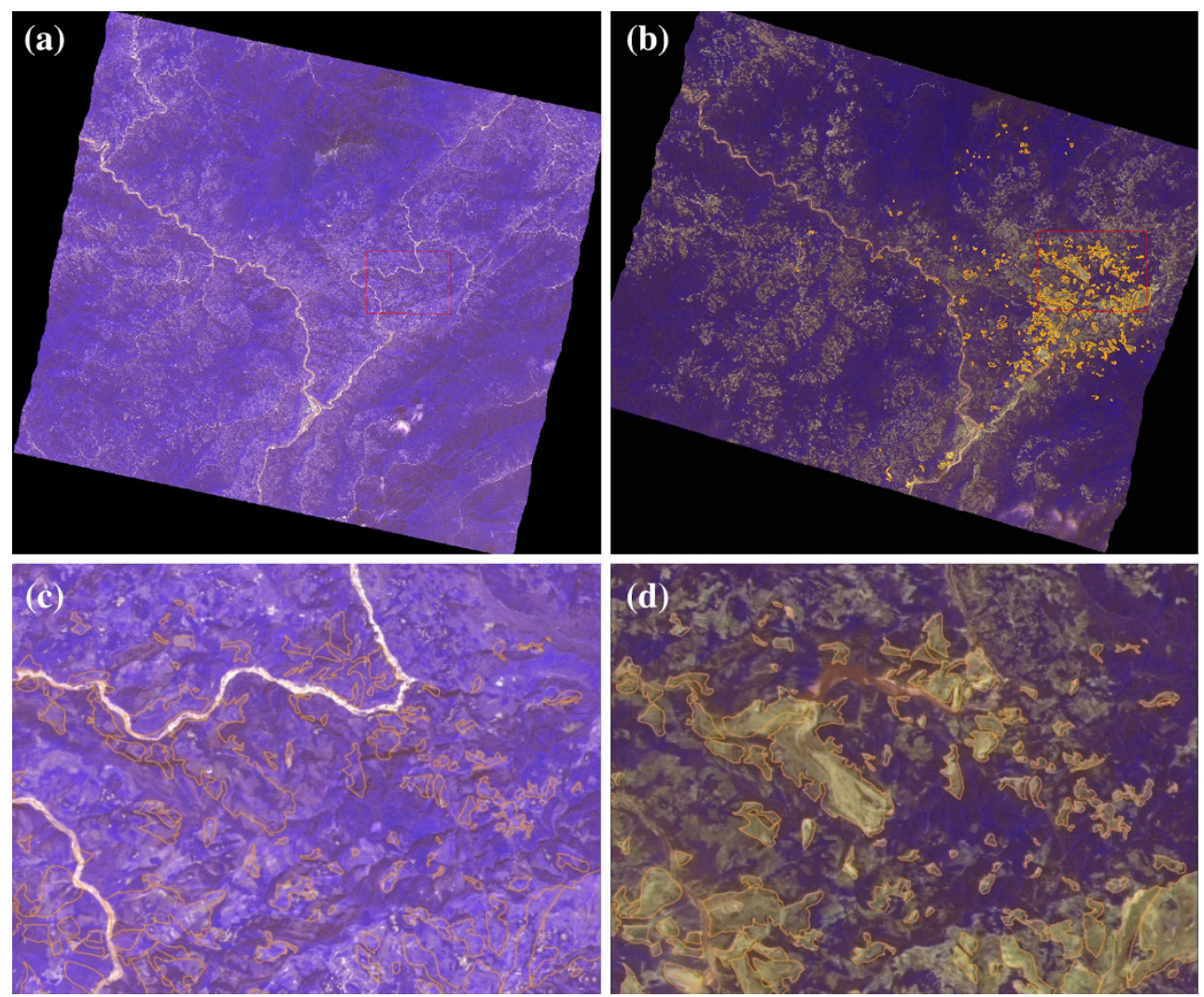

Fig. 2 Landslide inventory map for the study area. SPOT-5 composite image from 5 September 2006 (a); SPOT-5 composite image from 4 June 2008 (b); Sample area of the SPOT-5 composite image

estimations of $I_{\alpha}$ that are made using earthquake magnitude and source distance. In this paper, $\mathrm{I}_{\alpha}$ was calculated according to the equations in Jibson (1993) and Wang et al. (2010):

$\mathrm{I}_{\alpha}=0.9 \mathrm{~T} \hat{\alpha}^{2}$

$\log \mathrm{T}=0.432 \mathrm{M}-1.83$

where $\mathrm{T}$ is duration, $\hat{\alpha}$ is PGA (peak ground acceleration), and $\mathrm{M}$ is unspecified earthquake magnitude. The PGA of Zhou (2008) was adopted for these calculations.

One method for determining the Newmark displacement is to take the double integral of the seismic motion timehistory that exceeds the critical acceleration. However, it requires seismic motion data recorded from the stations close to the study areas, which may not be always available. An alternative method is to use empirical formulasfor example, the ones proposed by Jibson (1993) and Jibson et al. (1998), in which the Newmark displacement is a function of critical acceleration and Arias intensity. Recently, Hsieh and Lee (2011) modified and developed the empirical formulas for global soil-site and rock-site applications. In this article, we use the one for soil-sites (Hsieh and Lee 2011): from 5 September 2006 (c); Sample area of the SPOT-5 composite image from 4 June 2008 (d)

$\log D_{n}=0.802 \log \mathrm{I}_{\alpha}-10.981 A_{c}+7.377 A_{c} \log \mathrm{I}_{\alpha}+1.914$

Newmark displacement in the study area is shown in Fig. 3c.

In order to quantify the relationship between the calculated Newmark displacement and slope failure probability, we grouped grid cells into ten bins according to the values of the Newmark displacement $\left(D_{n}\right)$ using the geometrical classification method from ARC/INFO. The probability of slope failure was calculated based on the proportion of the cells with landslides occurrence in each bin. As shown in Fig. 4, the result indicates that the probability of slope failure increases as $D_{n}$ increases, especially when $D_{n}$ lies in the first few bins where the $D_{n}$ values are relatively small. A similar trend was also observed in the fitted curve of Jibson et al. (1998). But the probability of slope failure in this study area is in general smaller than in Jibson's result for all Newmark displacement levels. This suggests that in addition to Newmark displacement, other environmental factors characterizing regional geomorphologic and geographic profiles may also contribute to the landslides occurrence and distribution. 
Fig. 3 Map of factor of safety

(a), critical acceleration (b), and Newmark displacement (c) (a)

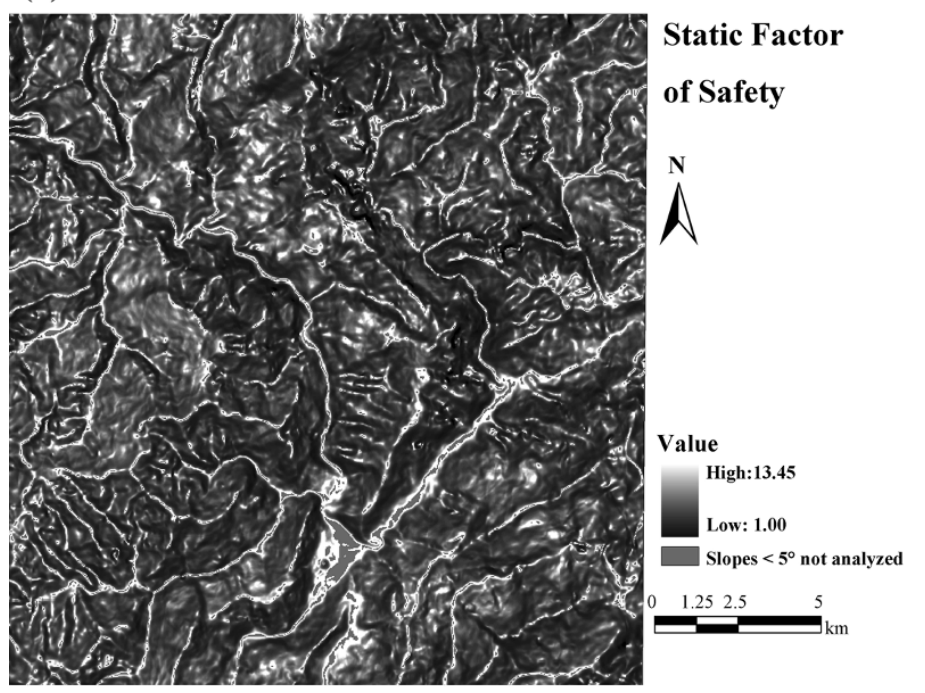

(b)

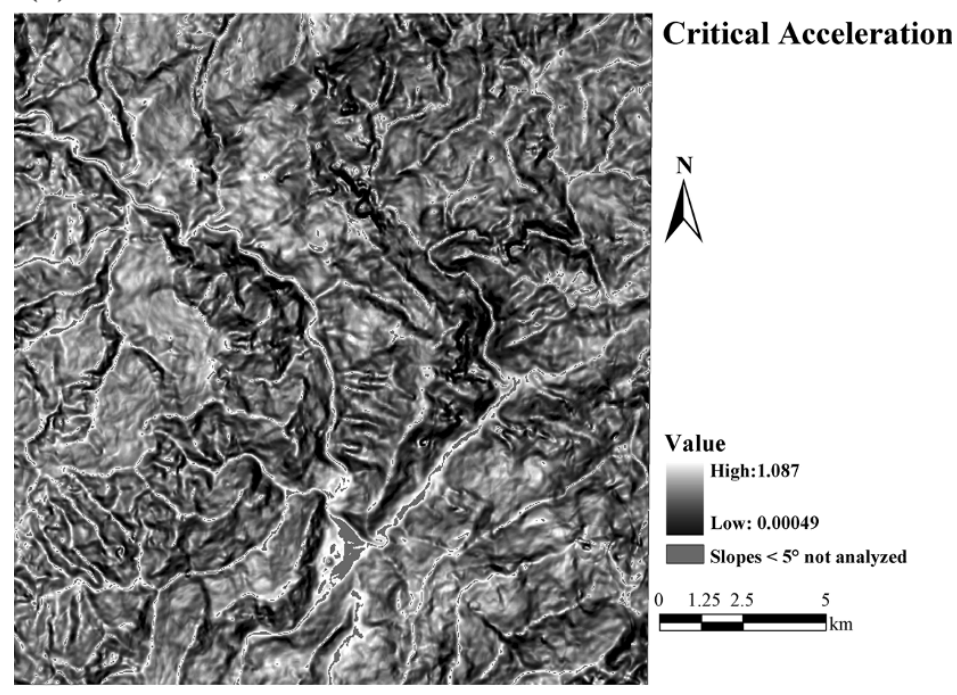

(c)

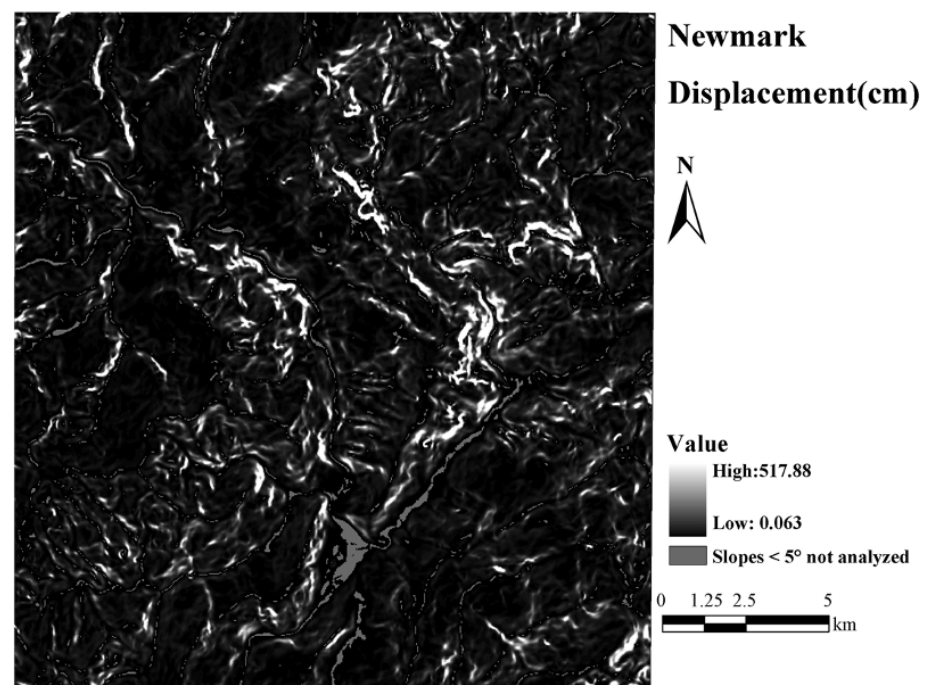




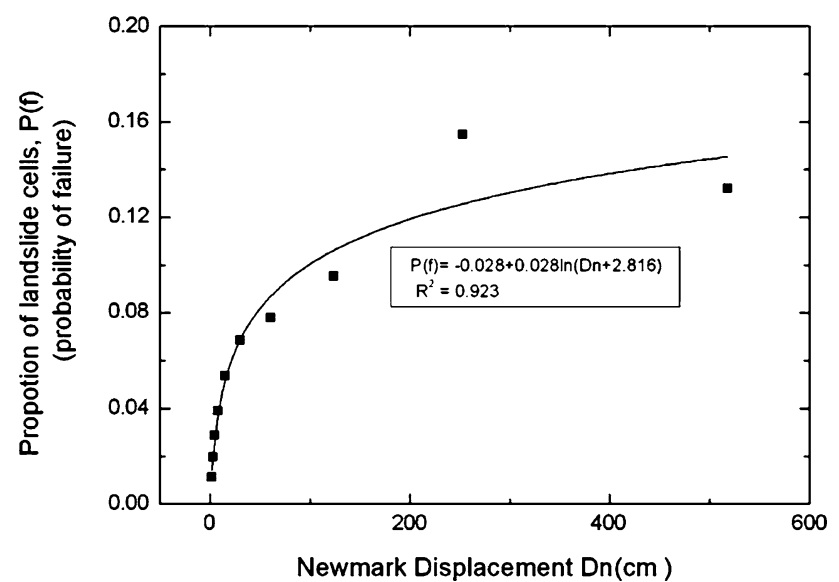

Fig. 4 Probability of slope failure as a function of Newmark displacement

\subsection{Environmental Factors}

In this study we examined the following environmental factors that are identified in the literature (Keefer 2000; Baeza and Corominas 2001; Duman et al. 2006; GarcíaRodríguez et al. 2008; García-Rodríguez and Malpica 2010; Hasegawa et al. 2008; Lee et al. 2008; Meunier et al. 2008; Lee et al. 2010) as possible landslide contributing factors: elevation (Digital Elevation Model, DEM), lithology, vegetation cover (represented by NDVI), land use, terrain roughness, relief degree of land surface (RDLS), profile curvature, and plan curvature. Lithology and land use are categorical variables, and the others are continuous variables. NDVI was obtained from the SPOT-5 satellite image taken on 5 September 2006 before the Wenchuan earthquake. The lithology variable was assigned based on the 1:2,500,000 geological map. Land-use information was obtained from the 1:500,000 Land Use Map of China. Terrain roughness, RDLS, profile curvature, and plan curvature were computed from the $30 \times 30 \mathrm{~m} \mathrm{DEM}$.

For all the continuous variables, we used the original values as the input for the regression model. For the nominal variables, two methods are usually used. One is to create a dummy variable for each of the $(n-1)$ classes of the nominal variable; this is effective but creates too many new variables (Choi et al. 2012; Lee 2004). Another method is to code the classes of the variable according to existing knowledge or expert experience (Carrara 1983; Ayalew and Yamagishi 2005; Nandi and Shakoor 2009; Bai et al. 2010). In this study, we adopted the second method and transformed the two nominal variables into landslide density, which is defined as:

Landslide density $=\left(B_{i} / A_{i}\right) / \sum_{i=1}^{N}\left(B_{i} / A_{i}\right)$.

Assuming one variable has $N$ classes. $A_{i}$ is the number of all pixels in the $i$-th class, and $B_{i}$ is the number of all landslide pixels in the same class. Table 1 shows the transformed results of the two nominal variables, and the normalized rate was used in the analysis to represent the values of the different classes of the Land use and Lithology variables. Maps of the environmental variables are shown in Fig. 5.

\subsection{Regression Model}

In this study, we aimed to distinguish between the influence of the triggering and environmental factors on the occurrence of earthquake-induced landslides. A logistic regression model (Lee 2004; Bai et al. 2010; Choi et al. 2012) was used to characterize the relationship between landslide occurrence (a binary variable) and the triggering and environmental factors.

The logistic model can be expressed as $P=\frac{1}{1+\mathrm{e}^{-z}}$, where $P$ is the occurrence probability ranging from 0 to $1 ; \mathrm{z}$ is the regression equation, $z=b_{0}+b_{1} x_{1}+b_{2} x_{2}+\cdots+b_{n} x_{n}$, for which the value varies from $-\infty$ to $+\infty ; b_{0}$ is the intercept of the model, $x_{i}$ is the $i$ th independent variable, and $b_{i}$ is the slope coefficient (or estimate) of the model for the variable $x_{i}$. Automatic spatial random sampling in

Table 1 Classification and transformation of the nominal variables

\begin{tabular}{llrrrr}
\hline Variables & Class & Failed Pixels & Total Pixels & Rate & Normalized Rate \\
\hline Land use & Farmland & 1,451 & 125,239 & 0.012 & 0.096 \\
& Wooded area & 3,603 & 238,109 & 0.015 & 0.125 \\
& Grassland & 5,551 & 70,487 & 0.079 & 0.650 \\
& Residential land & 13 & 831 & 0.016 & 0.129 \\
Lithology & 1. Cambrian and Ordovician systems & 9,749 & 155,828 & 0.063 & 0.786 \\
& 2. Devonian system/limestone, mudstone, Quartz sandstone & 0 & 21,826 & 0 & 0 \\
& 3. Mesoproterozoic/huili group,yanbian group & 4 & 7,579 & 0.001 & 0.007 \\
& 4. Monzonitic granite & 56 & 5,478 & 0.010 & 0.128 \\
& 5. Silurian system/killas, phyllite, tuff & 625 & 178,136 & 0.004 & 0.044 \\
& 6. Upper proterozoic/sinian system & 185 & 65,782 & 0.003 & 0.035 \\
\hline
\end{tabular}


(a)

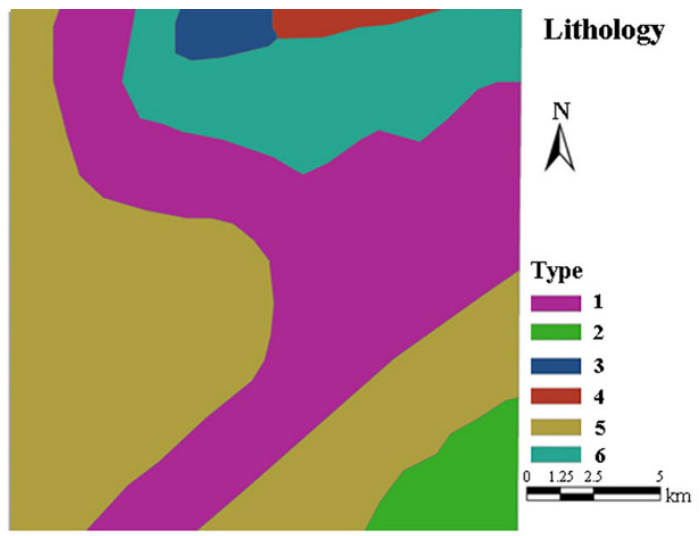

(c)

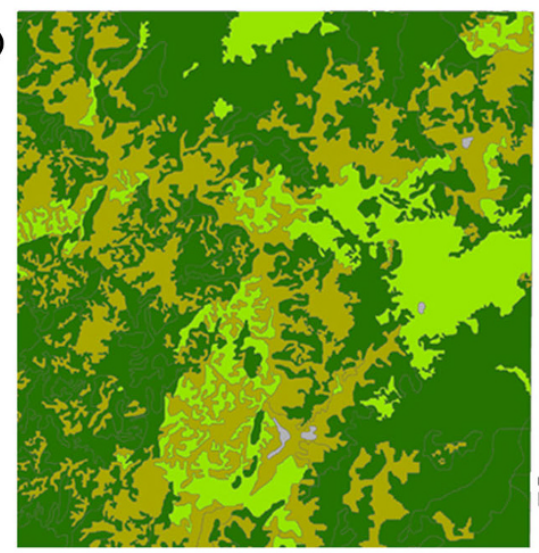

Land-use

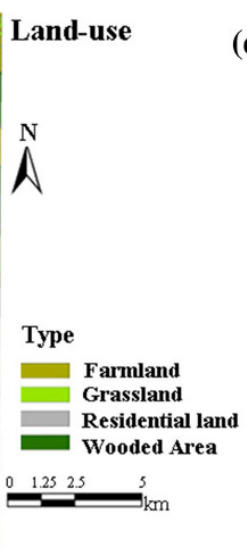

(e)

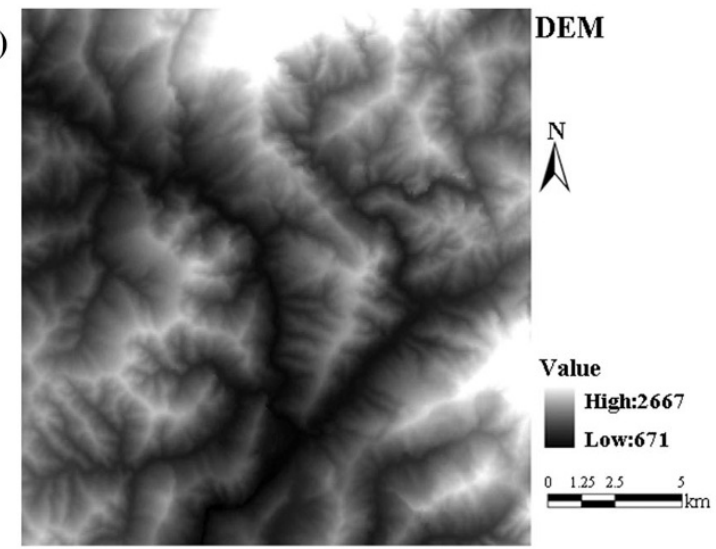

(g)

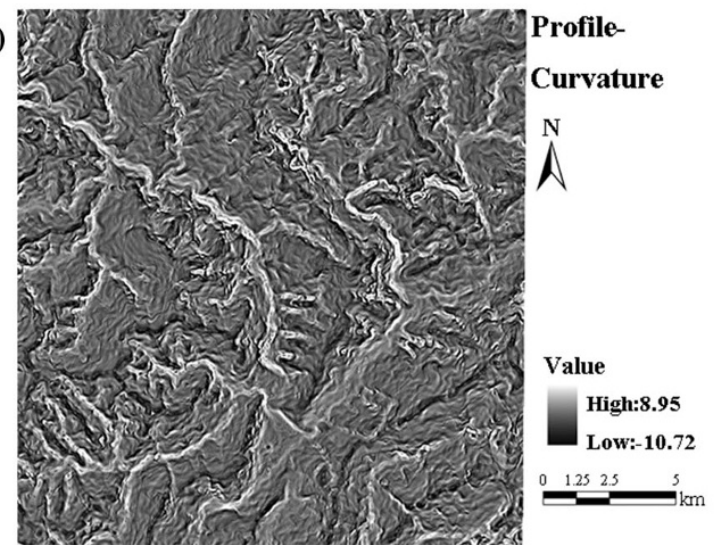

(b)

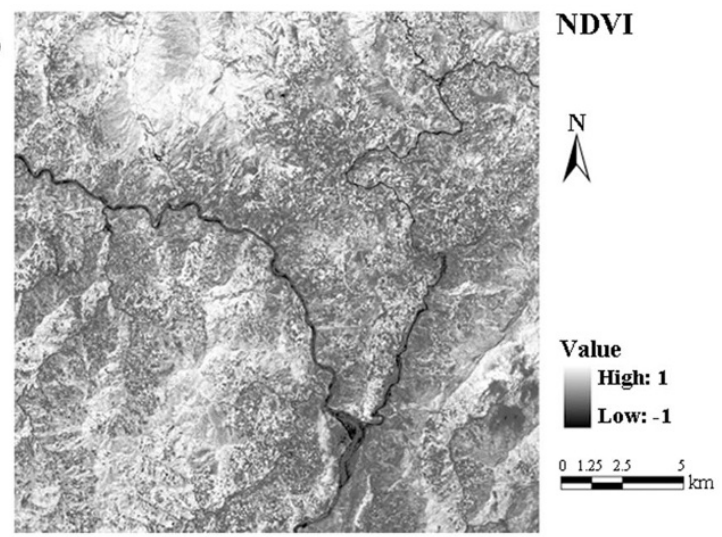

(d)

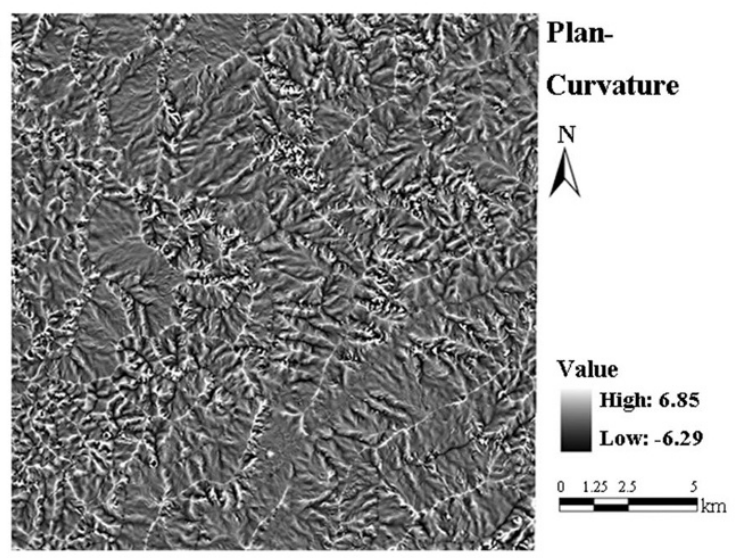

(f)

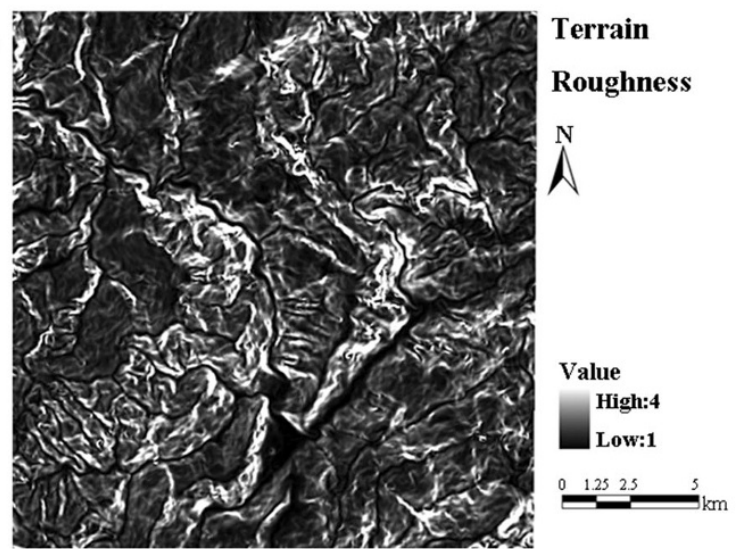

(h)

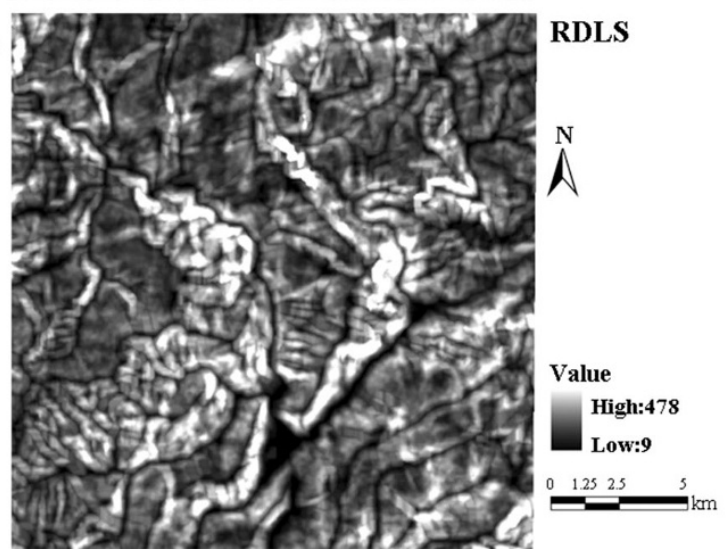


4Fig. 5 Maps of environmental factors (Lithology types in a 1 Cambrian and Ordovician systems, 2 Devonian system/limestone, mudstone, Quartz sandstone, 3 Mesoproterozoic/huili group, yanbian group, 4 Monzonitic granite, 5 Silurian system/killas, phyllite, tuff, 6 Upper proterozoic/sinian system)

ARC/INFO was applied to the areas without landslide to generate the same number of non-landslide samples as landslide samples, and the two sample datasets were used as the input of the regression model.

Collinearities among all the variables used in the regression model must be checked because the existence of highly correlated predictor variables can result in inaccurate prediction. A multicollinearity diagnosis for the linear regression was performed using the Statistical Package for the Social Sciences (SPSS). The values of the tolerance level (TOL) and the variance inflation factor (VIF) are shown in Table 2. The results indicate that all the tested variables except terrain roughness and RDLS passed the multicollinearity diagnosis at a tolerance level of at least 0.7. The variables terrain roughness and RDLS are excluded from the regression model since their tolerance levels are $<0.7$.

\section{Results}

We used a forward stepwise method to generate the regression model. The profile curvature variable was excluded in

Table 2 Multicollinearity diagnosis indices for independent variables

\begin{tabular}{lll}
\hline Variables & Tolerance & VIF \\
\hline DEM & 0.774 & 1.291 \\
NDVI & 0.816 & 1.225 \\
Land use & 0.848 & 1.179 \\
Profile curvature & 0.847 & 1.180 \\
Plan curvature & 0.872 & 1.147 \\
Lithology & 0.707 & 1.414 \\
$L_{n}\left(D_{n}\right)$ & 0.944 & 1.060 \\
\hline
\end{tabular}

the regression, even though it did pass the multicollinearity diagnosis. Therefore, the final regression model includes six explanatory variables, and the results are shown in Table 3. Higher Wald statistics imply a more significant contribution to the cause of a landslide. The significant levels show that all the variables are statistically significant in the model. The final Cox and Snell $R^{2}$ and Nagelkerke $R^{2}$ reached 0.408 and 0.544 respectively, which indicates a fairly good explanation for the landslide occurrence. The overall percentage of correctness of the model reached $81.2 \%$. This model can further be used to compute the susceptibility of regional landslide caused by earthquakes.

The Wald statistics indicate that lithology, as an environmental factor, is statistically the most significant factor in explaining landslide occurrences, followed by the natural logarithm of Newmark displacement. This implies that the Newmark displacement method suggested for regional-scale seismic hazard mapping needs to be incorporated with other environmental factors (that is, lithology types) in an integrated model. Although it is confirmed that greater Newmark displacements lead to a higher chance of landslide occurrence, lithology may dominate the regional distribution of coseismic landslides. This is particularly important if studied regions have significant geographic variation in lithology and other environmental factors that can significantly influence the regional formation and spatial distribution of landslides for a given triggering intensity.

Land use, NDVI, DEM, and plan curvature are also statistically significant. Lower NDVI leads to higher likelihood of landslides. Areas covered by forest tend to have fewer landslides. Local surface terrain (DEM and plan curvature) also contributes to landslide occurrence, but the effects are relatively minor when compared with lithology and Newmark displacement.

\section{Conclusion}

Much research has been undertaken in the field of susceptibility assessment of earthquake-induced landslides on

Table 3 Logistic regression coefficients and model fitting indicators

\begin{tabular}{lcllllll}
\hline Variables & Coefficient(B) & $\begin{array}{l}\text { Standard } \\
\text { Error (S.E.) }\end{array}$ & $\begin{array}{l}\text { Wald } \\
\text { Statistics }\end{array}$ & Significance. & $\begin{array}{l}\text { Cox and } \\
\text { Snell } R^{2}\end{array}$ & $\begin{array}{l}\text { Nagelkerke } \\
R^{2}\end{array}$ & $\begin{array}{l}\text { Overall Percentage } \\
\text { Correct }\end{array}$ \\
\hline Lithology & 3.795 & 0.067 & $3,175.112$ & $<0.01$ & 0.415 & 0.554 & $81.2 \%$ \\
$L_{n}\left(D_{n}\right)$ & 0.570 & 0.014 & $1,740.813$ & $<0.01$ & & \\
Land use & 2.190 & 0.076 & 833.346 & $<0.01$ & & \\
NDVI & -3.975 & 0.236 & 283.224 & $<0.01$ & & \\
DEM & 1.062 & 0.074 & 205.086 & $<0.01$ & & \\
Plan curvature & -0.504 & 0.053 & 90.799 & $<0.01$ & & \\
Constant & -3.258 & 0.127 & 657.530 & $<0.01$ & & \\
\hline
\end{tabular}


the basis of Newmark displacement calculation. In these cases, certain assumptions (that is, rigid block movement) are made to simplify the slope condition and facilitate practical calculations. Inevitably, such simplifications may neglect some environmental factors that are not embedded in the Newmark displacement calculation but that can dominate regional landslide formation. Previous research has confirmed that Newmark displacement, which combines seismic motion, soil properties, and slope geometry, plays an essential role in the occurrence of landslides. The approach of incorporating both triggering and environmental factors to create a more accurate forecast and assessment tool was attempted in this study by using a logistic regression model. In the model, we further differentiated the influence of Newmark displacement and other environmental factors on landslides occurrence. The results show that Newmark displacement (as a variable in which triggering factors are embedded) and lithology (as a primary environmental factor) equally dominated the regional formation and distribution of landslides induced by the Wenchuan earthquake in the study area. Many other environmental factors such as land use, NDVI, DEM, and plan curvature also significantly affected the susceptibility of the region to landslides. This integrated approach has proved to be effective and has enabled the practical analysis of the hazards of regional earthquake-induced landslides by fully considering the joint effects of both the earthquake and the regional environment.

Acknowledgments This research was supported by the National Natural Science Foundation of China under Grant 41101505 and the International Cooperation Project 2012DFG20710.

Open Access This article is distributed under the terms of the Creative Commons Attribution License which permits any use, distribution, and reproduction in any medium, provided the original author(s) and the source are credited.

\section{References}

Arias, A. 1970. A measure of earthquake intensity. In Seismic design for nuclear power plants, ed. R.J. Hansen, 438-483. Cambridge: Massachussetts Institute of Technology Press.

Ayalew, L., and H. Yamagishi. 2005. The application of GIS-based logistic regression for landslide susceptibility mapping in the Kakuda-Yahiko Mountains, central Japan. Geomorphology 65(1-2): 15-31.

Baeza, C., and J. Corominas. 2001. Assessment of shallow landslide susceptibility by means of multivariate statistical techniques. Earth Surface Processes and Landforms 26(12): 1251-1263.

Bai, S.B., J. Wang, G.N. Lü, P.G. Zhou, S.S. Hou, and S.N. Xu. 2010. GIS-based logistic regression for landslide susceptibility mapping of the Zhongxian segment in the Three Gorges area, China. Geomorphology 115(1-2): 23-31.

Carrara, A. 1983. Multivariate models for landslide hazard evaluation. Mathematical Geology 15(3): 403-426.
China Institute of Geo-Environment Monitoring. 2009. An imagebased study on typical geological hazards caused by Wenchuan Earthquake. Beijing: Geological Publishing House (in Chinese).

Chinese Academy of Sciences. n.d. International Scientific Data Service Platform. http://www.cnic.cn/zcfw/sjfw/gjkxsjjx/. Accessed May 2014.

Choi, J., H.J. Oh, H.J. Lee, C. Lee, and S. Lee. 2012. Combining landslide susceptibility maps obtained from frequency ratio, logistic regression, and artificial neural network models using ASTER images and GIS. Engineering Geology 124: 12-23.

Cruden, D.M. 1991. A simple definition of a landslide. Bulletin of the International Association of Engineering Geology 43(1): 27-29.

Duman, T.Y., T. Can, C. Gokceoglu, H.A. Nefeslioglu, and H. Sonmez. 2006. Application of logistic regression for landslide susceptibility zoning of Cekmece area, Istanbul, Turkey. Environment Geology 51(2): 241-256.

FEMA (Federal Emergency Management Agency). 2003. Multihazard loss estimation methodology earthquake model HAZUSMH MR3 technical manual. Washington, DC: FEMA.

García-Rodríguez, M.J., and J.A. Malpica. 2010. Assessment of earthquake-triggered landslide susceptibility in El Salvador based on an artificial neural network model. Natural Hazards and Earth System Sciences 10(6): 1307-1315.

García-Rodríguez, M.J., J.A. Malpica, B. Benitoa, and M. Díaz. 2008. Susceptibility assessment of earthquake-triggered landslides in El Salvador using logistic regression. Geomorphology 95(3): 172-191.

Hasegawa, S., A. Nonomur, R.K. Dahal, T. Yuichi, M. Haruki, and R. Yatabe. 2008. Geomorphological approach for earthquakeinduced landslides study. Proceedings of the International Conference on Disasters and Development, 94-105. http:// www.academia.edu/753464/Geomorphological_approach_for_ earthquake-induced_landslides_study. Accessed 19 May 2014.

Hsieh, S.Y., and C.T. Lee. 2011. Empirical estimation of the Newmark displacement from the Arias intensity and critical acceleration. Engineering Geology 122(1-2): 34-42.

Huang, R.Q., and W.L. Li. 2008. Research on development and distribution rules of geohazards induced by Wenchuan Earthquake on 12th May, 2008. Chinese Journal of Rock Mechanics and Engineering 27(12): 2585-2592 (in Chinese).

Jaiswal, P., C. van Westen, and V. Jetten. 2011. Quantitative assessment of landslide hazard along transportation lines using historical records. Landslides 8(3): 279-291.

Jibson, R.W. 1993. Predicting earthquake-induced landslide displacements using Newmark's sliding block analysis. Transportation Research Record 1411: 9-17.

Jibson, R.W., E.L. Harp, and J.A. Michael. 1998. A method for producing digital probabilistic seismic landslide hazard maps: An example from the Los Angeles California area. US Geological Survey Open-File Report 98-113. http://pubs.usgs.gov/of/ 1998/ofr-98-113/ofr-98-113.pdf. Accessed May 2014.

Jibson, R.W., E.L. Harp, and J.A. Michael. 2000. A method for producing digital probabilistic seismic landslide hazard maps. Engineering Geology 58(3-4): 271-289.

Keefer, D.K. 1984a. Landslides caused by earthquakes. Geological Society of America Bulletin 95: 406-421.

Keefer, D.K. 1984b. Rock avalanches caused by earthquakes: Source characteristics. Science 223(4642): 1288-1290.

Keefer, D.K. 2000. Statistical analysis of an earthquake-induced landslide distribution-The 1989 Loma Prieta, California event. Engineering Geology 58(3-4): 231-249.

Lee, S. 2004. Application of likelihood ratio and logistic regression models to landslide susceptibility mapping using GIS. Environmental Management 34(2): 223-232. 
Lee, E.M. 2009. Landslide risk assessment: The challenge of estimating the probability of landsliding. Quarterly Journal of Engineering Geology and Hydrogeology 42(4): 445-458.

Lee, C.T., C.C. Huang, J.F. Lee, K.L. Pan, M.L. Lin, and J.J. Dong. 2008. Statistical approach to earthquake-induced landslide susceptibility. Engineering Geology 100(1-2): 43-58.

Lee, S.T., T.T. Yu, W.F. Peng, and C.L. Wang. 2010. Incorporating the effects of topographic amplification in the analysis of earthquake-induced landslide hazards using logistic regression. Natural Hazards and Earth System Sciences 10(12): 2475-2488.

Li, T.J., Y. Zhao, K.L. Zhang, Y.S. Zheng, and Y. Wang. 2003. Soil geology. Beijing: Higher Education Press (in Chinese).

Liu, T.H., Z.Y. Shao, and Y.S. Luan. 2011. Geotechnical engineering technology and examples. Beijing: China Building Industry Press (in Chinese).

Meunier, P., N. Hovius, and J.A. Haines. 2008. Topographic site effects and the location of earthquake induced landslides. Earth and Planetary Science Letters 275(3-4): 221-232.

Nandi, A., and A. Shakoor. 2009. A GIS-based landslide susceptibility evaluation using bivariate and multivariate statistical analyses. Engineering Geology 110(1-2): 11-20.

NDRC (National Development and Reform Commission)-Ministry of Science and Technology/Expert Group on Earthquake Relief. 2008. Comprehensive analysis and evaluation on Wenchuan Earthquake. Beijing: Economic Science Press (in Chinese).

Newmark, N.M. 1965. Effects of earthquakes on dams and embankments. Geotechnique 15(2): 139-160.

Nichol, J., and M.S. Wong. 2005. Satellite remote sensing for detailed landslide inventories using change detection and image fusion. International Journal of Remote Sensing 26(9): 1913-1926.

Proske, H., K. Granica, M. Hirschmugl, and M. Wurm. 2008. Landslide detection and susceptibility mapping using innovative remote sensing data sources. Proceedings Interpraevent 2: 219-229 Dornbirn, May 2008.

Qi, S.W., Q. Xu, C.L. Liu, B. Zhang, N. Liang, and L.Q. Tong. 2009. Slope instabilities in the severest disaster areas of 5.12 Wenchuan Earthquake. Journal of Engineering Geology 17(1): 39-49 (in Chinese).

Rajabi, A.M., M.R. Mahdavifar, M. Khamehchiyan, and V. Del Gaudio. 2011. A new empirical estimator of coseismic landslide displacement for Zagros Mountain region (Iran). Natural Hazards 59(2): 1189-1203.
Rodriguez-Peces, M.J., J.L. Perez-Garcia, J. Garcia-Mayordomo, J.M. Azanon, J.M. Insua-Arevalo, and J. Delgado-Garcia. 2011. Applicability of Newmark method at regional, sub-regional and site scales: Seismically induced Bullas and La Paca rockslide cases (Murcia, SE Spain). Natural Hazards 59(2): $1109-1124$.

Sarkar, S., and D.P. Kanungo. 2004. An integrated approach for landslide susceptibility mapping using remote sensing and GIS. Photogrammetric Engineering \& Remote Sensing 70(5): 617-625.

Tralli, D.M., R.G. Blom, V. Zlotnicki, A. Donnellan, and D.L. Evans. 2005. Satellite remote sensing of earthquake, volcano, flood, landslide and coastal inundation hazards. Journal of Photogrammetry \& Remote Sensing 59(4): 185-198.

van Westen, C.J., T.W.J. van Asch, and R. Soeters. 2006. Landslide hazard and risk zonation-Why is it still so difficult? Bulletin of Engineering Geology and the Environment 65(2): 167-184.

Wang, X.Y., G.Z. Nie, and N. Zhang. 2010. Relationship between landslides introduced by the Wenchuan Earthquake and Arias intensity. Journal of Basic Science and Engineering 18(4): 645-656 (in Chinese).

Wasowski, J., D.K. Keefer, and C.T. Lee. 2011. Toward next generation of research on earthquake-induced landslides: Current issues and future challenges. Engineering Geology 122(1-2): $1-8$.

Wilson, R.C., and D.K. Keefer. 1983. Dynamic analysis of a slope failure from the 6 August 1979 Coyote Lake, California, earthquake. Bulletin of the Seismological Society of America 73(3): 863-877.

Xu, Q., and W.L. Li. 2010. Distribution of large scale landslides induced by the Wenchuan Earthquake. Journal of Engineering Geology 18(6): 818-826 (in Chinese).

Yang, W.T., M. Wang, and P.J. Shi. 2013. Using MODIS NDVI time series to identify geographic patterns of landslides in vegetated regions. IEEE Geoscience and Remote Sensing Letters 10(4): $707-710$.

Zhou, Z.H. 2008. The strong ground motion recordings of the Ms8.0 Wenchuan Earthquake in Sichuan Province. Earthquake Research in Sichuan 4: 25-29 (in Chinese). 